\title{
Incidence of clinically relevant medication errors in the era of electronically prepopulated medication reconciliation forms: a retrospective chart review
}

\author{
Kaitlin R. Stockton MD, Maeve E. Wickham MSc, Simon Lai BSc, Katherin Badke BScPharm, \\ Karen Dahri PharmD, Diane Villanyi MD, Vi Ho MD, Corinne M. Hohl MD
}

\section{Abstract}

Background: To reduce medication discrepancies (unintended differences between a patient's outpatient and inpatient medication regimens), Canadian institutions have implemented medication reconciliation forms that are prepopulated with outpatient medication dispensing data. These may prompt prescribers to reorder discontinued medications or continue newly contraindicated medications. Our objective was to evaluate the incidence of medication discrepancies and errors of commission after the implementation of such forms.

Methods: This retrospective chart review included patients previously enrolled in an observational study in which a research pharmacist prospectively collected best-possible medication histories in the emergency department. Research assistants uninvolved with the parent study compared medication orders written in the first 48 hours after admission with the research pharmacist's best-possible medication history to identify medication discrepancies and errors of commission, defined as inappropriate medication continuations and reordering of previously stopped medications. An independent panel adjudicated the clinical significance of the errors.

Results: Of 151 patients, 71 (47.0\% [95\% confidence interval (CI) 39.2-54.9]) were exposed to 112 medication errors on admission. Of the 112 errors, $24(21.4 \%$ [95\% Cl 14.9-29.9]) were clinically significant. Errors of commission accounted for $24.1 \%(27 / 112$ [95\% Cl 17.3-32.8]) of all errors; 10 (37.0\% [95\% Cl 18.8-55.2]) of the errors of commission were clinically significant.

Interpretation: Medication errors were common after the implementation of electronically prepopulated medication reconciliation forms. Prospective research is required to examine the impact of prepopulated medication reconciliation forms and ensure they do not facilitate errors of commission.

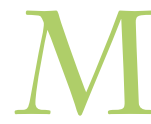
edication discrepancies are unintended differences between a patient's outpatient and inpatient medication regimens. They affect up to $60 \%$ of patients admitted to hospital. ${ }^{1,2}$ Medication discrepancies can lead to adverse drug events — unintended and harmful effects associated with medications ${ }^{1-3}$ - which are a common cause of preventable iatrogenic morbidity and mortality. ${ }^{4-6}$

Medication reconciliation is a required organizational practice in Canadian hospitals. ${ }^{7}$ It involves obtaining and documenting a best-possible medication history on admission in order to improve communication at care transitions and prevent medication discrepancies. ${ }^{7}$ Several international studies have shown a reduction in medication discrepancies among inpatients following the implementation of medication reconciliation interventions. ${ }^{8-14}$ However, most published interventions relied heavily on pharmacists, limiting their generalizability to institutions with adequate pharmacy resources. Most Canadian hospitals have insufficient clinical pharmacists and rely on physicians, nurses and clinical trainees to complete medication reconciliation, even though these people often lack the time to take a thorough medication history. ${ }^{15-18}$

To facilitate medication history-taking and eliminate transcribing errors, hospitals in jurisdictions with access to elec-

\section{Competing interests: None declared.}

This article has been peer reviewed.

Correspondence to: Kaitlin Stockton, kaitlinrstockton@gmail.com CMAJ Open 2017. DOI:10.9778/cmajo.20170023 
tronic medication dispensing records have developed medication reconciliation forms that are prepopulated with outpatient medication dispensing data. Yet, such databases do not capture medications dispensed outside of community pharmacies (e.g., in long-term care facilities) and may list inaccurate dosages of medications titrated by patients or care providers (e.g., warfarin). ${ }^{19,20}$ Prepopulated medication reconciliation forms may facilitate errors of commission by prompting health care providers to restart a discontinued medication that remains in the electronic medication dispensing history or to continue a medication in the setting of a new contraindication. Our objective was to evaluate the incidence of medication discrepancies and errors of commission after implementation of an electronically prepopulated medication reconciliation form. A secondary objective was to evaluate factors associated with both types of error.

\section{Methods}

\section{Design}

We conducted a structured 2-staged chart review at Vancouver General Hospital, a 955-bed academic tertiary care centre. This was an a priori planned substudy of a large prospective observational cohort study that aimed to validate previously derived clinical decision rules to identify patients at high risk for adverse drug events. ${ }^{21}$

\section{Participants}

We included patients who had been enrolled into the prospective study and were subsequently admitted to hospital between Oct. 1, 2014 and Aug. 31, 2015. Patients had been enrolled into the prospective study by means of a systematic selection algorithm to minimize selection bias and ensure a representative sample. ${ }^{21} \mathrm{We}$ included patients who were 19 years of age or older, spoke English or had an interpreter available, and had taken at least 1 prescription or over-thecounter medication within 2 weeks of presenting to the emergency department. We excluded patients whose charts were unavailable for review and those with a hospital stay lasting less than 24 hours.

\section{Definitions}

We defined a medication discrepancy as any unexplained difference between medication orders documented on medication reconciliation forms or other order sheets within 48 hours of admission and a best-possible medication history recorded by a research pharmacist. Discrepancies included discontinuations and omissions of home medications; changes in the dosage, route or frequency of administration; and ordering an "as needed" medication regularly or vice versa (Table 1). We defined an error of commission as reordering a medication that had been previously stopped or inappropriately continuing a medication known to exacerbate a patient's clinical condition (e.g., continuing an antihypertensive in the setting of hypotension). We did not consider substituting a brand-name medication for its generic equivalent or an agent within the same pharmacologic class as discrepancies. We excluded discrepancies involving herbal products, vitamins and supplements.

We rated clinical severity based on a previously published classification system: ${ }^{1}$ class I errors were those deemed "unlikely to cause patient discomfort or clinical deterioration," class II errors had "the potential to cause moderate discomfort or clinical deterioration," and class III errors were defined as having "the potential to result in severe discomfort or clinical deterioration."

\section{Collection of best-possible medication history data}

During the prospective study, a research pharmacist (K.B.) collected and documented a best-possible medication history for all patients in the emergency department using a variety of information sources including patient and family member interviews, PharmaNet (British Columbia's electronic medication dispensing database), nursing home medication records, medication bottles, blister packs and collateral sources of information, if required. We retained the pharmacist-collected best-possible medication history in the research records of the parent study and considered it to be the gold standard.

\section{Chart review methods}

\section{Stage 1}

Two research assistants (K.S. and S.L.) uninvolved in the parent study and blinded to the best-possible medication history collected by the research pharmacist reviewed the charts of eligible patients after they had been discharged from hospital. The research assistants abstracted all medication orders written within 48 hours of admission, including those documented on medication reconciliation forms (Figure 1) and regular order sheets, using a standardized data collection form. They also recorded demographic data and clinical information pertaining to the admission. To assess interrater reliability, the research assistants independently reviewed a random sample of 20 charts during a pilot period. All data were collected with the use of Epi Info version 7.1.4 (Centers for Disease Control and Prevention).

\section{Stage 2}

One of the research assistants (K.S.), a medical resident, then compared admission orders identified during stage 1 with the research pharmacist's best-possible medication history and documented medication discrepancies and errors of commission. If errors were identified, the entire chart was reviewed for any adverse drug events that occurred during the admission as a result of the error. During the pilot period, it became apparent that we could not determine intentionality retrospectively. Therefore, we categorized inappropriate discrepancies as "unexplained" or "explained." We categorized discrepancies as explained when we found evidence in nursing or physician notes, or in laboratory or diagnostic data, that warranted holding the medication (e.g., holding an angiotensin-converting-enzyme inhibitor in the setting of an elevated creatinine level). Explained discrepancies were not considered errors. 


\section{Stage 3}

An adjudication panel consisting of an internist and geriatrician (D.V.), an emergency physician (C.H.) and a clinical pharmacist (K.D.), all of whom were uninvolved in stages 1 and 2, independently adjudicated medication errors according to their potential to cause harm. All disagreements were resolved by discussion. We calculated the interrater reliability among the 3 members of the adjudication panel for classifying the type and severity of errors by collapsing class II and III discrepancies into a single category.

\section{Statistical analysis}

We computed descriptive statistics for demographic variables and medication error classifications, and reported summary statistics as means and standard deviations for continuous variables, and as proportions with $95 \%$ confidence intervals (CIs) for categorical variables. We assessed the agreement between raters by calculating Fleiss $\kappa$ scores with $95 \%$ CIs. ${ }^{22}$ We analyzed the association between unexplained discrepancies and potentially important variables using nonparametric MannWhitney tests, as the outcome data did not follow a normal distribution. Potentially important variables were determined by a literature review on medication discrepancies and adverse drug events. ${ }^{1,21}$ We used logistic regression to examine univariate associations between the occurrence of a discrepancy and key predictor variables, then built a regression model to calculate the adjusted odds of occurrence of a discrepancy. The sample size was determined by the primary study.

\begin{tabular}{|c|c|c|}
\hline Type of error & Definition & Example \\
\hline \multicolumn{3}{|l|}{ Medication discrepancy } \\
\hline Discontinuation & $\begin{array}{l}\text { Discontinuing a patient's regular } \\
\text { medication without explanation }\end{array}$ & $\begin{array}{l}\text { Patient is taking } 20 \mathrm{mg} \text { of citalopram at } \\
\text { home, but this is discontinued on } \\
\text { admission to hospital }\end{array}$ \\
\hline Omission & $\begin{array}{l}\text { Patient's regular medication is not } \\
\text { listed on medication reconciliation } \\
\text { form and is not reordered }\end{array}$ & $\begin{array}{l}\text { Patient is taking } 81 \mathrm{mg} \text { of acetylsalicylic } \\
\text { acid (over the counter) daily, but this is } \\
\text { not listed on medication reconciliation } \\
\text { form. It is not ordered during hospital stay. }\end{array}$ \\
\hline Change in dosage & $\begin{array}{l}\text { Medication is ordered at dosage } \\
\text { indicated on medication } \\
\text { reconciliation form, but patient is } \\
\text { taking different dosage }\end{array}$ & $\begin{array}{l}\text { Patient was prescribed } 25 \mathrm{mg} \text { of } \\
\text { metoprolol twice daily, but family doctor } \\
\text { had decreased dosage to } 12.5 \mathrm{mg} \text { by } \\
\text { mouth twice daily. Patient receives } 25 \mathrm{mg} \\
\text { twice daily in hospital without indication } \\
\text { for increased dosage. }\end{array}$ \\
\hline Change in route & $\begin{array}{l}\text { Medication is ordered via route } \\
\text { indicated on medication } \\
\text { reconciliation form, but patient is } \\
\text { taking it differently at home }\end{array}$ & $\begin{array}{l}\text { Patient was prescribed acetaminophen, } \\
1000 \mathrm{mg} \text { by mouth } 3 \text { times daily per } \\
\text { rectum, in nursing facility because of } \\
\text { decreased level of consciousness. It is } \\
\text { ordered by mouth in hospital. }\end{array}$ \\
\hline Change in frequency & $\begin{array}{l}\text { Medication is ordered at frequency } \\
\text { indicated on medication } \\
\text { reconciliation form, which differs } \\
\text { from patient's regimen }\end{array}$ & $\begin{array}{l}\text { Patient was prescribed gabapentin, } \\
300 \mathrm{mg} 3 \text { times daily, but is taking it only } \\
\text { at bedtime because of daytime } \\
\text { somnolence. Medication is ordered as } \\
300 \mathrm{mg} 3 \text { times daily in hospital. }\end{array}$ \\
\hline As needed to regular & $\begin{array}{l}\text { Medication is ordered regularly as } \\
\text { per medication reconciliation form, } \\
\text { but patient is taking it as needed }\end{array}$ & $\begin{array}{l}\text { Patient was prescribed zopliclone, } 7.5 \mathrm{mg} \\
\text { at bedtime, but is using it as needed, and } \\
\text { only infrequently. It is ordered regularly in } \\
\text { hospital. }\end{array}$ \\
\hline Regular to as needed & $\begin{array}{l}\text { Medication is ordered as needed } \\
\text { as per medication reconciliation } \\
\text { form, but the patient is taking it } \\
\text { regularly }\end{array}$ & $\begin{array}{l}\text { Patient was prescribed lorazepam, } \\
0.5-1 \mathrm{mg} 3 \text { times daily as needed, but is } \\
\text { taking } 1 \mathrm{mg} 3 \text { times daily regularly. It is } \\
\text { ordered as needed in hospital. }\end{array}$ \\
\hline \multicolumn{3}{|l|}{ Error of commission } \\
\hline Reorder error & $\begin{array}{l}\text { Reordering a medication that had } \\
\text { previously been stopped }\end{array}$ & $\begin{array}{l}\text { Patient was prescribed indomethacin for } \\
\text { acute gout flare-up but had stopped it } \\
\text { when flare-up subsided. It is erroneously } \\
\text { reordered in hospital. }\end{array}$ \\
\hline Inappropriate continuation & $\begin{array}{l}\text { Ordering a medication that patient } \\
\text { is taking in the setting of a new } \\
\text { contraindication }\end{array}$ & $\begin{array}{l}\text { Patient is taking indomethacin for acute } \\
\text { gout flare-up and then presents with } \\
\text { gastrointestinal bleed. Indomethacin is } \\
\text { inappropriately continued in hospital. }\end{array}$ \\
\hline
\end{tabular}




\section{OPEN}

Research

\section{Ethics approval}

The University of British Columbia Clinical Research Ethics Board approved the study protocol and waived the need for informed consent.

\section{Results}

Of the 189 patients enrolled in the primary study who were admitted to hospital, 38 were excluded: in 27 cases the chart

\section{IF YOU RECEIVED THIS FACSIMILE IN ERROR,}

PLEASE CALL 999-999-9999 IMMEDIATELY

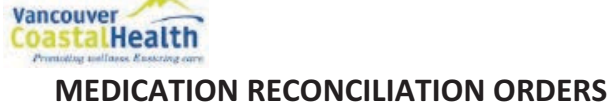

Clinical Information as per PharmaNet:

Adverse Reaction(s) as per PharmaNet (refer to facility-specific documentation for current status): NKDA

\section{PATIENT, TEST \\ Birthdate: 1955 Jun $2 \quad$ Gender: $F$ \\ PHN: $\quad$ BC-XXXXXXXXX}

\begin{tabular}{|c|c|c|}
\hline \multicolumn{2}{|c|}{ Medication History } & \multirow{2}{*}{$\begin{array}{c}\text { Request medical interpreter: 604-675-4099 } \\
\text { Medication Orders }\end{array}$} \\
\hline $\begin{array}{l}\text { Medications as per PharmaNet } \\
\text { on } 2016 \text { Oct } 01 \text { 09:04 }\end{array}$ & $\begin{array}{l}\text { Verified with: } \\
\square \text { patient } \square \text { other: }\end{array}$ & \\
\hline $\begin{array}{l}\text { FLUTICASONE PROPRIONATE } 250 \text { MCG } \\
\text { HFA AER } \\
\text { INHALE } 1 \text { PUFF ONCE DAILY (RINSE } \\
\text { MOUTH AFTER USE) } \\
\text { 2016Sept15 Qty: } 120.0 \text { Filled } \\
\text { BROWN CPSID: } 91 / 02797 \\
\text { (Max Daily Dose: } 1.000 \text { per PharmaNet) }\end{array}$ & $\begin{array}{l}\square \text { Taking differently (specify): } \\
\square \text { Per PharmaNet } \\
\square \text { No longer taking } \square \text { Unable to verify } \\
\text { Last taken at: }\end{array}$ & $\begin{array}{l}\square \text { Give as per verified history } \\
\square \text { Give as per PharmaNet } \\
\square \text { Discontinue } \\
\square \text { Change to: }\end{array}$ \\
\hline MORPHINE 60 MG ER CAP & $\begin{array}{l}\square \text { Taking differently (specify): } \\
\square \text { Per PharmaNet } \\
\square \text { No longer taking } \square \text { Unable to verify }\end{array}$ & $\begin{array}{l}\square \text { Give as per verified history } \\
\square \text { Give as per PharmaNet } \\
\square \text { Discontinue }\end{array}$ \\
\hline $\begin{array}{l}\text { 2016Sept15 Qty: } 60.0 \text { Filled } \\
\text { BROWN CPSID: } 91 / 02797 \\
\text { (Max Daily Dose: } 1.000 \text { per PharmaNet) }\end{array}$ & Last taken at: & $\square$ Change to: \\
\hline MORPHINE 5 MG TAB & $\square$ Taking differently (specify): & $\square$ Give as per verified history \\
\hline $\begin{array}{l}\text { TAKE } 1 \text { TABLET EVERY } 4 \text { HOURS WHEN } \\
\text { NEEDED FOR BREAK THROUGH PAIN } \\
2016 \text { Sept15 Qty: } 28.0 \text { Filled } \\
\text { BROWN CPSID: } 91 / 02797 \\
\text { (Max Daily Dose: } 1.000 \text { per PharmaNet) }\end{array}$ & $\begin{array}{l}\square \text { Per PharmaNet } \\
\square \text { No longer taking } \square \text { Unable to verify } \\
\text { Last taken at: }\end{array}$ & $\begin{array}{l}\square \text { Give as per PharmaNet } \\
\square \text { Discontinue } \\
\square \text { Change to: }\end{array}$ \\
\hline
\end{tabular}

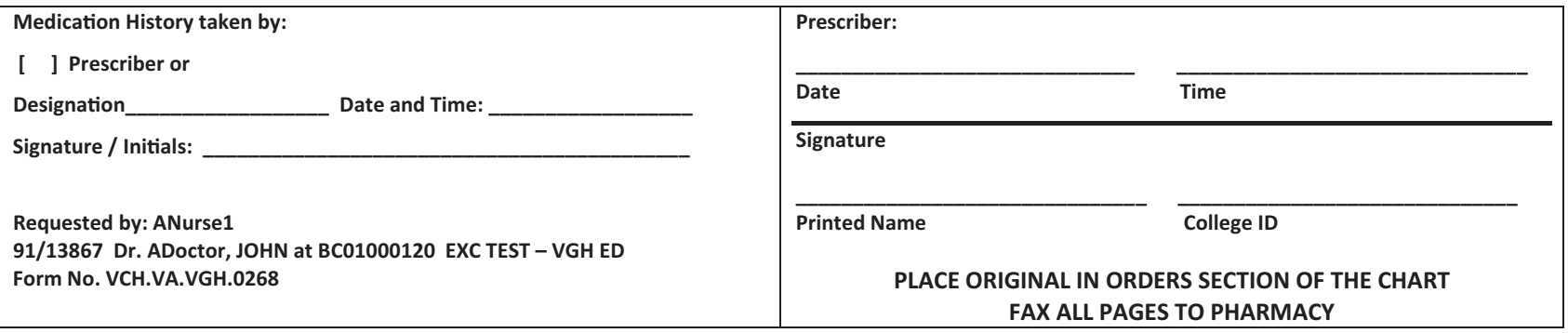

Figure 1: Prepopulated medication reconciliation form for a hypothetical patient. Electronic medication dispensing data from PharmaNet are used to automatically prepopulate medication reconciliation forms. A member of the health care team must verify the patient's medication history and note in the middle column any discrepancies between the prepopulated information and how the patient is taking the medication. The treating physician then indicates in the right-hand column whether to continue or alter the medication. 
was not available for review, 8 patients had a stay of less than 24 hours, and 3 patients had an incomplete best-possible medication history. Thus, we reviewed the charts of 151 patients. The mean age of the participants was 66.8 (standard deviation $18.8)$ years, and $80(53.0 \%)$ were male (Table 2$)$. The mean number of medications on admission was 6.8 (standard deviation 4.7), and the most common admitting diagnoses were pneumonia, cancer and sepsis.

The interrater reliability between research assistants in documenting medication orders was 0.91 ( $\kappa 95 \%$ CI $0.78-1.0$ ). Eight patients did not have a prepopulated medication reconciliation form in their chart. Of the 143 charts containing medication reconciliation forms, 46 (32.2\% [95\% CI 25.0-40.2]) had the medication verification section (i.e., middle column of the form; Figure 1) completed by a health care provider (residents in 18 cases [39\% (95\% CI 26.4-53.6)], clinical pharmacists in 12 cases [26\% (95\% CI 15.6-40.3)], medical students in 9 cases [20\% (95\% CI 10.7-3.3.2)], attending physicians in 6 cases $[13 \%(95 \%$ CI $6.2-25.7)]$ and a nurse in 1 case $[2 \%(95 \%$ CI $0.5-11.2)]$ ). In all the other charts, health care providers simply ticked off boxes to order medications in the third column, without completing the medication verification section.

\section{Incidence of medication errors}

Of the 151 patients, 71 (47.0\% [95\% CI 39.2-54.9]) were exposed to 112 medication errors on admission. We identified 85/112 (75.9\% [95\% CI 67.1-82.9]) unexplained medication discrepancies among 49 patients (Table 3). Most of the discrepancies were categorized as inappropriate discontinuations (32/85 [38\% (95\% CI 27.3-47.9)]) and omissions (24/85 [28\% (95\% CI 18.6-37.8)]). A total of $27 / 112$ (24.1\% [95\% CI 17.3-32.8]) errors of commission were identified among 22 patients (Table 3). These included 10 inappropriate continuations of contraindicated medications (37\% [95\% CI 21.5-55.9]) and 17 reorder errors of previously stopped medications (63\% [95\% CI 44.1-78.5]).

\section{Clinical significance}

The interrater reliability among the 3 members of the adjudication panel for classifying the severity of errors was 0.33 ( $\kappa 95 \%$ CI $0.28-0.42$ ). Thirteen of the 85 medication discrepancies (15\% [95\% CI 10.1-25.7]) were deemed as having the potential to cause moderate harm (class II), and 1 (1\% [95\% CI 0.0-3.5]) was classified as having the potential to result in severe clinical deterioration (class III) (Table 3). Of the 27 identified errors of commission, 10 (37\% [95\% CI 18.8-55.2]) were assigned a class II rating, and none were assigned a class III rating. Of the 24 clinically significant (class II and class III) errors, 6 (25\% [95\% CI 12.1-45.1]) involved continuing a patient's antihypertensive medication in the setting of symptomatic hypotension, and 4 (17\% [95\% CI 6.8-36.1]) were an omission of low-dosage acetylsalicylic acid (Table 4). We found no documented adverse drug events as a result of medication errors.

\section{Factors associated with medication errors}

Univariate analysis indicated that taking 8 or more medications and the presence of cognitive impairment were associated with unexplained medication discrepancies $(p<0.001, p=0.05$, respectively) (Table 5). Similarly, taking 8 or more medications was associated with errors of commission $(p=0.02)$.

Multivariable analyses indicated that taking 8 or more medications was associated with a fivefold greater odds of experiencing 1 or more medication discrepancies or errors of commission (odds ratio 5.05 [95\% CI 2.44-10.46], $p<0.001$ ) after known confounders were controlled for (Table 6). Age, sex, timing of admission and length of admission were not associated with the occurrence of medication discrepancies or errors of commission.

\section{Interpretation}

We found at least 1 medication discrepancy or error of commission in the charts of $47.0 \%$ of enrolled patients. Errors of

\section{Table 2: Characteristics of participants}

\begin{tabular}{lc}
\hline & No. $(\%)^{*}$ \\
Characteristic & $n=151$
\end{tabular}

Sex

\begin{tabular}{|cc|}
\hline Male & $80(53.0)$ \\
\hline Female & $71(47.0)$ \\
\hline Age, mean \pm SD, yr & $66.8 \pm 18.8$ \\
\hline Length of hospital stay, median (IQR), d & $6(3-13)$
\end{tabular}

Most responsible diagnosis

Pneumonia 14 (9.3)

Cancer $11(7.3)$

Sepsis $9(6.0)$

Stroke syndrome 8 (5.3)

Extremity fracture 7 (4.6)

Upper gastrointestinal bleed $6(4.0)$

Chronic obstructive pulmonary disease 4 (2.6)

Skin/soft tissue infection 4 (2.6)

Bipolar affective disorder $4(2.6)$

Asthma $3(2.0)$

Comorbid condition

Hypertension 68 (45.0)

Dyslipidemia 29 (19.2)

Diabetes mellitus type $2 \quad 25$ (16.6)

Atrial fibrillation 24 (15.9)

Depression/anxiety 21 (13.9)

Hypothyroidism 21 (13.9)

Gastroesophageal reflux disease 20 (13.2)

Coronary artery disease 19 (12.6)

Congestive heart failure 18 (11.9)

Osteoarthritis 18 (11.9)

No. of medications on admission, mean $\quad 6.8 \pm 4.7$ $\pm \mathrm{SD}$

Note: IQR = interquartile range, SD = standard deviation.

${ }^{\star}$ Except where noted otherwise. 


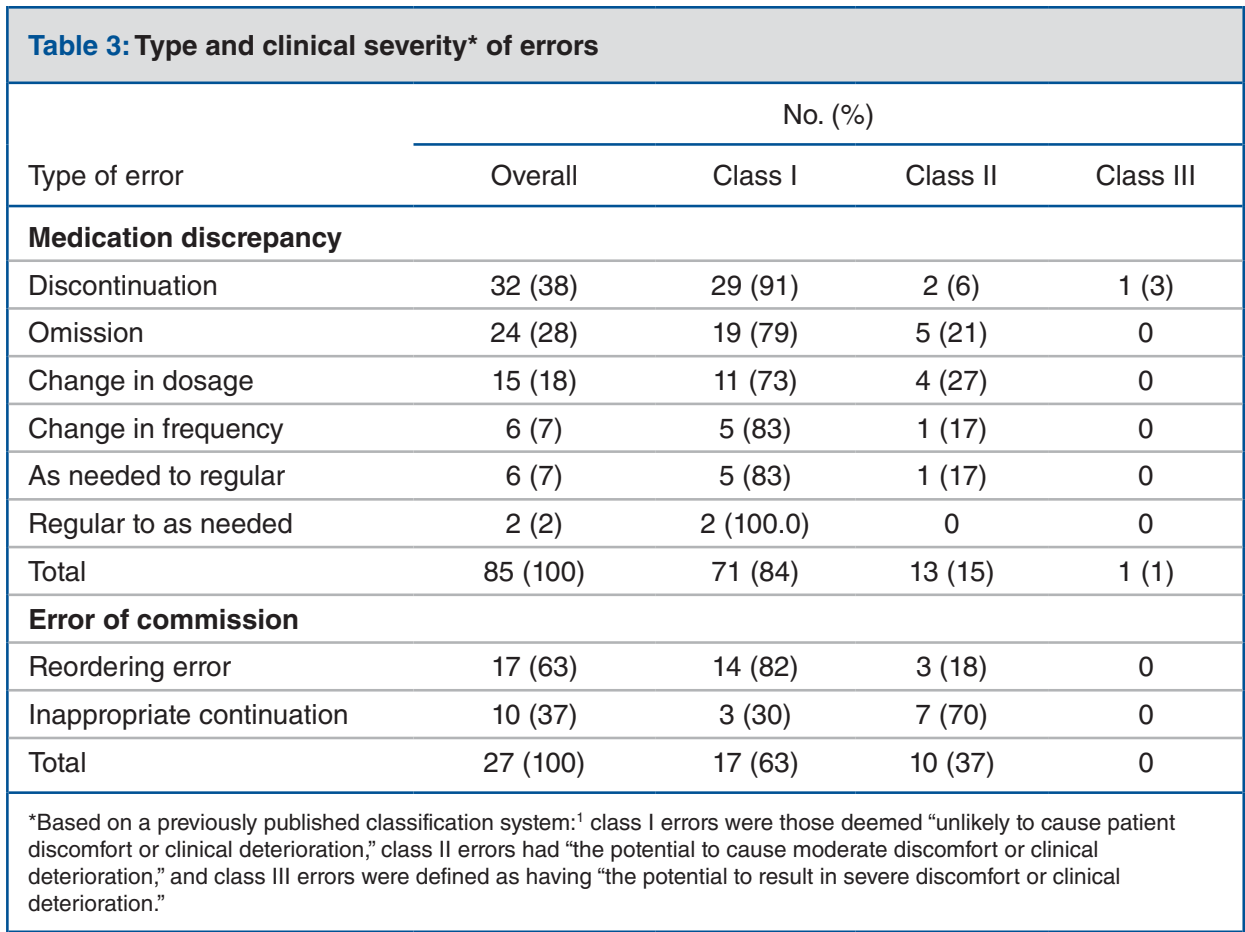

commission were found in $14.6 \%$ of the charts, of which $37.0 \%$ were clinically significant. The medication history section of prepopulated medication reconciliation forms was left blank in $67.8 \%$ of the charts.

We found a lower incidence of medication discrepancies overall (32.4\% [49 of 151 patients] v. 53.6\%) and of clinically significant discrepancies (16.5\% v. 38.6\%) than Cornish and colleagues, ${ }^{1}$ who conducted a prospective study in a Canadian teaching hospital without access to electronic medication dispensing data. Kalb and colleagues ${ }^{2}$ conducted a small prospective study following the launch of PharmaNet but before the implementation of prepopulated medication reconciliation forms and reported discrepancies among $60 \%$ of inpatients, $43 \%$ of which were deemed clinically significant. International studies with varied methodologies have shown unintentional medication discrepancies among $27 \%-54 \%$ of patients, $11 \%-$ $59 \%$ of which were deemed to be clinically important. ${ }^{5,6,23}$

We found a high incidence of errors of commission compared with Cornish and colleagues ${ }^{1}(17.9 \%$ v. $0 \%)$. Our reported incidence is similar to that reported by Kalb and colleagues, ${ }^{2} 27 \%$, after PharmaNet data became available to hospital prescribers. Our finding may be a reflection of prescribers' overreliance on dispensing data in lieu of taking a careful medication history and verifying medication dispensing data. This overreliance may be compounded by the ease of ticking boxes on prepopulated forms. Although our study was not comparative, and we therefore cannot determine the impact of prepopulated medication reconciliation forms on the incidence of medication discrepancies or errors of commission, our data suggest that errors of commission occur frequently when medication dispensing data are available to prescribers. These types of error are as harmful as, or potentially more harmful than, the medication discrepancies that reconciliation processes were designed to prevent.

Most patients in our study did not have medication histories verified on the medication reconciliation form, and only 12 patients $(8.4 \%)$ had medication histories documented by clinical pharmacists. Several studies have shown a reduction in both overall and clinically significant medication discrepancies when clinical pharmacists are involved in reconciling medications. This suggests that clinical pharmacist resources should be made available for medication reconciliation processes in Canadian acute care hospitals., ${ }^{3,14,24,25}$ Given the scarcity of pharmacist resources in Canada, this may be feasible only for patients at high risk for adverse drug events. Based on our findings, this may include patients taking at least 8 medications and those with cognitive impairment. Our data are consistent with a recent Canadian study that showed a significant increase in medication discrepancies among patients prescribed at least 7 medications on discharge. ${ }^{26}$

\section{Limitations}

Our study has several limitations. Our sample size was limited by enrolment into the parent study. Our study was retrospective, and, therefore, we were unable to confirm intentionality for the identified discrepancies when clinical notes were unclear. Although the interrater reliability on the collection of medication orders was excellent, the interrater reliability on rating their clinical significance was only fair. This likely reflects the varied clinical backgrounds of our adjudication panel members as well as the complexity of determining the potential clinical significance of a medication error in the absence of an adverse drug event. Although we used a prospectively collected best-possible medication history obtained 
Table 4: Description of the 24 identified errors classified as class II/III errors

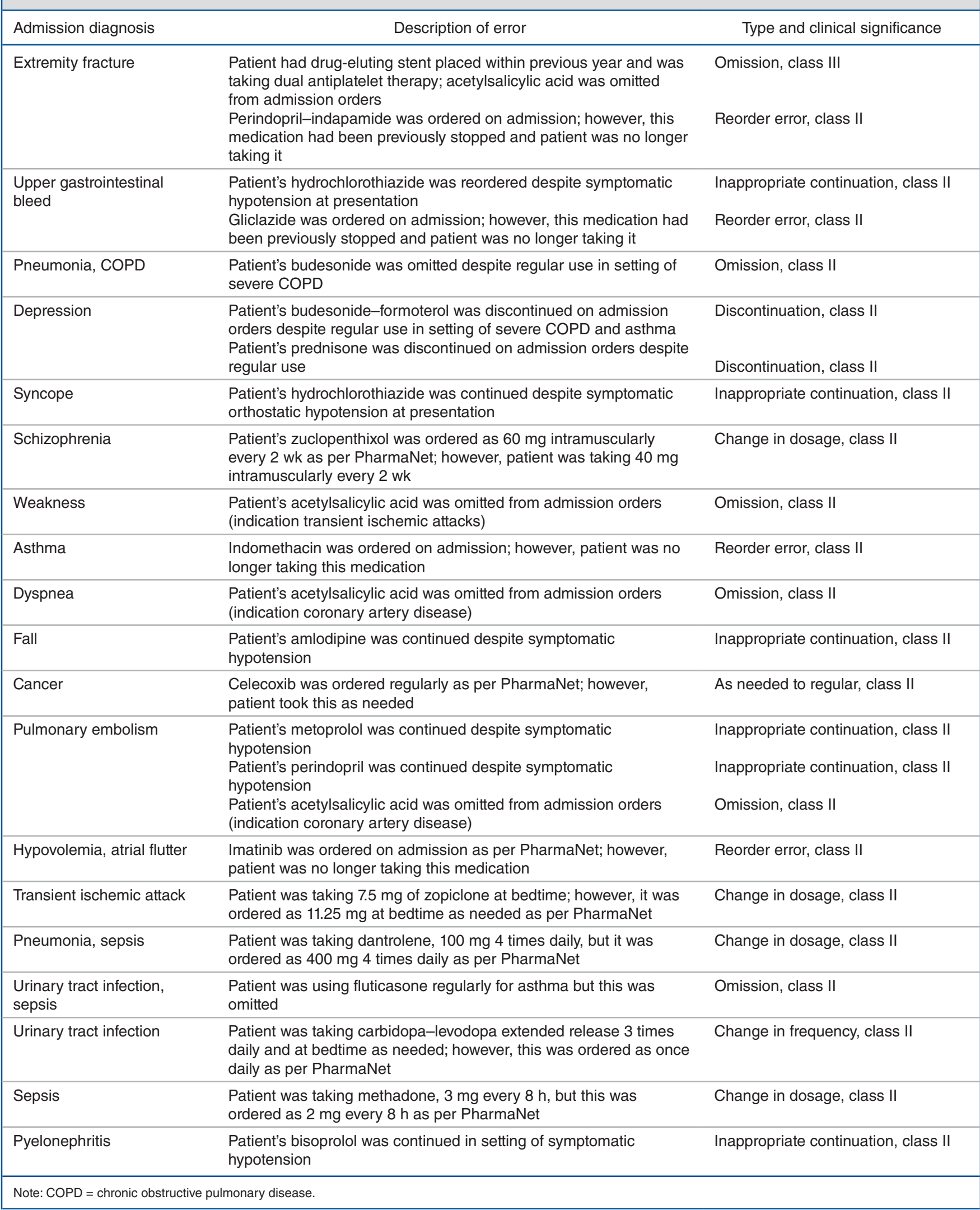




\begin{tabular}{|c|c|c|c|}
\hline \multirow[b]{2}{*}{ Type of error; characteristic } & \multicolumn{2}{|c|}{$\begin{array}{l}\text { No. of errors per patient, } \\
\text { mean } \pm \text { SD }\end{array}$} & \multirow[b]{2}{*}{ Difference $(95 \% \mathrm{Cl})$} \\
\hline & $\begin{array}{c}\text { With } \\
\text { characteristic }\end{array}$ & $\begin{array}{c}\text { Without } \\
\text { characteristic }\end{array}$ & \\
\hline \multicolumn{4}{|l|}{ Medication discrepancy } \\
\hline Nighttime admission (after 8 pm) & $0.43 \pm 0.81$ & $0.61 \pm 1.11$ & $0.18(-0.19$ to 0.57$)$ \\
\hline Length of stay $\geq 48 \mathrm{hr}$ & $0.57 \pm 1.06$ & $0.46 \pm 0.78$ & $-0.11(-0.71$ to 0.49$)$ \\
\hline Age $\geq 80 \mathrm{yr}$ & $0.75 \pm 1.28$ & $0.48 \pm 0.89$ & $-0.27(-0.63$ to 0.08$)$ \\
\hline Female sex & $0.63 \pm 1.11$ & $0.50 \pm 0.97$ & $-0.13(-0.47$ to 0.20$)$ \\
\hline $\begin{array}{l}\geq 8 \text { medications on best-possible } \\
\text { medication history }\end{array}$ & $1.09 \pm 1.41$ & $0.24 \pm 0.50$ & $-0.84(-1.16$ to -0.53$)$ \\
\hline $\begin{array}{l}\text { Prepopulated medication } \\
\text { reconciliation form }\end{array}$ & $0.55 \pm 1.05$ & $0.75 \pm 0.89$ & $0.20(-0.55$ to 0.94$)$ \\
\hline Cognitive impairment & $1.31 \pm 1.84$ & $0.49 \pm 0.91$ & $-0.81(-1.40$ to -0.23$)$ \\
\hline \multicolumn{4}{|l|}{ Error of commission } \\
\hline Nighttime admission (after 8 pm) & $0.20 \pm 0.46$ & $0.17 \pm 0.46$ & $-0.03(-0.20$ to 0.14$)$ \\
\hline Length of stay $\geq 48 \mathrm{hr}$ & $0.17 \pm 0.45$ & $0.23 \pm 0.60$ & $0.06(-0.21$ to 0.32$)$ \\
\hline Age $\geq 80 \mathrm{yr}$ & $0.21 \pm 0.50$ & $0.17 \pm 0.44$ & $-0.04(-0.20$ to 0.12$)$ \\
\hline Female sex & $0.24 \pm 0.55$ & $0.13 \pm 0.37$ & $-0.11(-0.26$ to 0.03$)$ \\
\hline $\begin{array}{l}\geq 8 \text { medications on best-possible } \\
\text { medication history }\end{array}$ & $0.28 \pm 0.56$ & $0.12 \pm 0.38$ & $-0.16(-0.32$ to -0.01$)$ \\
\hline $\begin{array}{l}\text { Prepopulated medication } \\
\text { reconciliation form }\end{array}$ & $0.18 \pm 0.47$ & $0.13 \pm 0.35$ & $-0.06(-0.39$ to 0.28$)$ \\
\hline Cognitive impairment & $0.15 \pm 0.38$ & $0.18 \pm 0.47$ & $0.03(-0.24$ to 0.29$)$ \\
\hline
\end{tabular}

Table 6: Univariate and multivariate associations of patient characteristics with medication discrepancies or errors of commission

\begin{tabular}{|lcc|}
\hline Characteristic & $\begin{array}{c}\text { Unadjusted OR } \\
(95 \% \mathrm{Cl})\end{array}$ & $\begin{array}{c}\text { Adjusted OR } \\
(95 \% \mathrm{Cl})^{\star}\end{array}$ \\
\hline Age $\geq 80 \mathrm{yr}$ & $1.64(0.82-3.29)$ & $1.14(0.50-2.64)$ \\
\hline Female sex & $1.52(0.79-2.93)$ & $1.52(0.74-3.12)$ \\
\hline $\begin{array}{l}\geq 8 \text { medications on } \\
\text { best possible } \\
\text { medication history }\end{array}$ & $5.00(2.45-10.17)$ & $5.05(2.44-10.46)$ \\
\hline $\begin{array}{l}\text { Cognitive } \\
\text { impairment }\end{array}$ & $2.64(0.82-8.52)$ & $2.29(0.55-9.58)$ \\
\hline $\begin{array}{l}\text { Medication history } \\
\text { not verified }\end{array}$ & $0.84(0.42-1.70$ & $1.10(0.49-2.44)$ \\
\hline
\end{tabular}

Note: $\mathrm{Cl}=$ confidence interval, $\mathrm{OR}=$ odds ratio.

*Adjusted for age, sex, cognitive impairment, $\geq 8$ medications on best-possible medication history and not having a medication history completed.

by a research pharmacist as our gold standard, in many cases this information was obtained when the patient was ill, and it is possible that errors occurred during this process. This study was conducted at a large teaching hospital, and the findings may not be generalizable to community settings. Finally, medication discrepancies and errors of commission may result from different patient and/or hospital factors and should therefore be investigated separately in future studies with larger samples.

\section{Conclusion}

Despite the implementation of a medication reconciliation process informed by electronic medication dispensing data, clinically relevant medication errors were common in our study. We documented clinically significant errors of commission due to reordering medications that had previously been stopped and continuing medications that had the potential to cause harm. Currently, electronic medication dispensing databases do not contain discontinuation orders, which is an important omission. Prospective comparative studies are needed to evaluate the impact of prepopulating medication reconciliation forms with electronic medication dispensing data on various types of error, particularly on errors of commission that are clinically significant. Our results highlight that the availability of medication dispensing data to inform medication reconciliation does not negate the need to conduct and document a thorough best-possible medication history. Future research is needed to identify patients who are at the highest risk for the occurrence of medication discrepancies and errors of commission in order 
to optimize our use of scarce pharmacist resources in medication reconciliation processes.

\section{References}

1. Cornish PL, Knowles SR, Marchesano R, et al. Unintended medication discrepancies at the time of hospital admission. Arch Intern Med 2005;165:424-9.

2. Kalb K, Shalansky S, Legal M, et al. Unintended medication discrepancies associated with reliance on prescription databases for medication reconciliation on admission to a general medical ward. Can 7 Hosp Pharm 2009;62:284-9.

3. Mueller SK, Sponsler KC, Kripalani S, et al. Hospital-based medication reconciliation practices: a systematic review. Arch Intern Med 2012;172:1057-69.

4. Classen DC, Pestotnik SL, Evans RS, et al. Adverse drug events in hospitalized patients. Excess length of stay, extra costs, and attributable mortality. 7AMA 1997;277:301-6.

5. Tam VC, Knowles SR, Cornish PL, et al. Frequency, type and clinical importance of medication history errors at admission to hospital: a systematic review. CMA7 2005;173:510-5.

6. Quélennec B, Beretz L, Paya D, et al. Potential clinical impact of medication discrepancies at hospital admission. Eur 7 Intern Med 2013;24:530-5.

7. Accreditation Canada/Canadian Institute for Health Information/Canadian Patient Safety Institute/Institute for Safe Medication Practices Canada. Medication reconciliation in Canada: raising the bar - progress to date and the course ahead. Ottawa: Accreditation Canada; 2012.

8. Agrawal A, Wu WY. Reducing medication errors and improving systems reliability using an electronic medication reconciliation system. Ft Comm 7 Qual Patient Saf 2009;35:106-14.

9. Poole DL, Chainakul JN, Pearson M, et al. Medication reconciliation: a necessity in promoting a safe hospital discharge. F Healthc Qual 2006;28:12-9.

10. Boockvar KS, Blum S, Kugler A, et al. Effect of admission medication reconciliation on adverse drug events from admission medication changes. Arch Intern Med 2011;171:860-1.

11. Murphy EM, Oxencis CJ, Klauck JA, et al. Medication reconciliation at an academic medical center: implementation of a comprehensive program from admission to discharge. Am 7 Health Syst Pharm 2009;66:2126-31.

12. Schnipper JL, Hamann C, Ndumele CD, et al. Effect of an electronic medication reconciliation application and process redesign on potential adverse drug events: a cluster-randomized trial. Arch Intern Med 2009;169:771-80.

13. Schnipper JL, Kirwin JL, Cotugno MC, et al. Role of pharmacist counseling in preventing adverse drug events after hospitalization. Arch Intern Med 2006; $166: 565-71$

14. Mekonnen AB, McLachlan AJ, Brien JAE. Pharmacy-led medication reconciliation programmes at hospital transitions: a systematic review and metaanalysis. 7 Clin Pharm Ther 2016;41:128-44.

15. Meguerditchian AN, Krotneva S, Reidel K, et al. Medication reconciliation at admission and discharge: a time and motion study. BMC Health Serv Res 2013;13:485.

16. Pippins JR, Gandhi TK, Hamann C, et al. Classifying and predicting errors of inpatient medication reconciliation. 7 Gen Intern Med 2008;23:1414-22.

17. Gleason KM, McDaniel MR, Feinglass J, et al. Results of the Medications At Transitions and Clinical Handoffs (MATCH) study: an analysis of medication reconciliation errors and risk factors at hospital admission. 7 Gen Intern Med 2010;25:441-7.

18. Wanbon R, Lyder C, Villeneuve E, et al. Medication reconciliation practices in Canadian emergency departments: a national survey. Can 7 Hosp Pharm 2015;68:202-9.

19. Price M, Bowen M, Lau F, et al. Assessing accuracy of an electronic provincial medication repository. BMC Med Inform Decis Mak 2012;12:42.

20. Shalansky S, Jang L, Ignaszewski A, et al. Accuracy of a prescription claims database for medication reconciliation for outpatients with heart failure. Can 7 Hosp Pharm 2007;60:1-8.

21. Hohl CM, Yu E, Hunte GS, et al. Clinical decision rules to improve the detection of adverse drug events in emergency department patients. Acad Emerg Med 2012;19:640-9.

22. Fleiss JL. Measuring nominal scale agreement among many raters. Psychol Bull 1971;76:378-82

23. Kwan JL, Lo L, Sampson M, et al. Medication reconciliation during transitions of care as a patient safety strategy: a systematic review. Ann Intern Med 2013; 158:397-403.

24. Leguelinel-Blache G, Arnaud F, Bouvet S, et al. Impact of admission medication reconciliation performed by clinical pharmacists on medication safety. Eur 7 Intern Med 2014;25:808-14.

25. Alex S, Adenew AB, Arundel C, et al. Medication errors despite using electronic health records: the value of a clinical pharmacist service in reducing discharge-related medication errors. Qual Manag Health Care 2016;25:32-7.

26. Shiu JR, Fradette M, Padwal RS, et al. Medication discrepancies associated with a medication reconciliation program and clinical outcomes after hospital discharge. Pharmacotherapy 2016;36:415-21.

Affiliations: Departments of Family Medicine (Stockton) and Emergency Medicine (Wickham, Hohl), Faculty of Medicine (Lai), University of British Columbia; Department of Pharmaceutical Sciences (Badke, Dahri), Vancouver General Hospital; Faculty of Pharmaceutical Sciences (Dahri), University of British Columbia; Department of Internal Medicine (Villanyi) and Emergency Department (Ho, Hohl), Vancouver General Hospital, Vancouver, BC

Contributors: Kaitlin Stockton and Corinne Hohl conceived the study; Simon Lai, Katherin Badke, Kaitlin Stockton and Vi Ho collected the data; Karen Dahri, Diane Villanyi and Corinne Hohl adjudicated the outcomes; Maeve Wickham cleaned the data and analyzed them under the supervision of Kaitlin Stockton and Corine Hohl; and Kaitlin Stockton drafted the manuscript and revised it with intellectual and editorial input from all the other authors. All of the authors approved the final version to be published and agreed to act as guarantors of the work.

Funding: Kaitlin Stockton was supported by a Canadian Association of Emergency Physicians Research Competition grant.

Supplemental information: For reviewer comments and the original submission of this manuscript, please see www.cmajopen.ca/content/5/2/ E345/suppl/DC1 